\title{
UTILIZAÇÃO DE UMA FERRAMENTA MULTIMÍDIA PARA IDENTIFICAÇÃO DE ARTRÓPODES: AVALIAÇÃO DE ESTUDANTES DO ENSINO FUNDAMENTAL
}

\author{
Application of a multimedia tool to identify Arthropods: \\ evaluation of students in elementary school
}

Tiago José Benedito Eugênio ${ }^{1}$

Resumo: No presente artigo apresentamos um modelo de montagem e produção de um CD-ROM com recursos para identificação de 22 animais, que disponibiliza, para o aluno, uma chave multimídia para identificação de artrópodes. Tratamos de avaliar esta chave multimídia como ferramenta didática em quatro turmas (sétimo, oitavo e nono ano do Ensino Fundamental) de uma escola privada do município de Parnamirim, RN. A avaliação foi dividida em duas etapas: avaliação através de questionário imediatamente após o contato com a chave multimídia, e comparação entre as notas obtidas em exames por escrito de alunos que tiveram e não tiveram contato com a ferramenta didática. Ao todo, 89 alunos participaram das duas etapas da avaliação. Constatamos, de forma geral, uma avaliação positiva e um desempenho significativamente maior dos alunos que interagiram com a ferramenta didática no exame por escrito.

Palavras-chave: Didática. Tecnologia na educação. Artrópodes. Taxonomia. Ensino de Biologia.

\begin{abstract}
In this article we have used a CD-ROM, which offers the student a multimedia key to identify 22 species of arthropods. We evaluate this key multimedia tool for teaching in classes of elementary school (seventh, eighth and ninth years ) at a private school in the city of Parnamirim in the state of Rio Grande do Norte, Brazil. The evaluation was divided into two stages: assessment by questionnaire after contact with key media; and a comparison with the marks obtained in the test of students who had and not had contact with the multimedia tool. In all, 89 students participated in both stages of evaluation. We find, overall, a positive evaluation and a significantly higher performance of students in the test who interacted with the multimedia.
\end{abstract}

Keywords: Educational technology. Arthropods. Taxonomy. Biology teaching.

\footnotetext{
${ }^{1}$ Centro de Biociências, Departamento de Fisiologia, Programa de Pós-graduação em Psicobiologia, Universidade Federal do Rio Grande do Norte (UFRN). Campus universitário, caixa postal 1511. Lagoa Nova, Natal, RN, Brasil.59.078-970. tiagoeugenio20@gmail.com
} 


\section{Introdução}

Zelar pelo ensino com qualidade da biodiversidade e dos preceitos taxonômicos é essencial para introduzir o indivíduo ao pensamento biológico (MAYR, 1998; FUTUYMA, 2002). O ensino de ciências, sobretudo da taxonomia e da zoologia, é marcado pelo excesso de substantivos e definições dadas para os objetos, sejam eles vivos ou não. Assim, é frequente o aluno associar uma proposta, por exemplo, o conhecimento da biodiversidade, com uma necessidade de decorar os numerosos nomes de seres, de processos e de definições. Isso ocorre, pois a maioria dos métodos de avaliação visa exclusivamente a isso, quantificar o volume de informações assimiladas pelo aluno - que, na maioria das vezes, não tem o menor significado para aquele. Ações dessa natureza apenas fomentam o repúdio a todo este conhecimento e desvaloriza a curiosidade do indivíduo acerca dos ambientes e dos seres vivos, bem como não convida os alunos a discutirem por que e para que as classificações biológicas existem. Ainda, não explica os papéis dos diferentes seres vivos nos ambientes, nem suas complexas interrelações com o meio e com os outros indivíduos.

Nesse sentido, é mais do que necessário o professor ser habilitado para mediar o volume de informações, as ferramentas pelas quais essas são transmitidas e, sobretudo, a contextualização e lógica dada a essas informações. Acreditamos que o professor, de Ciências e Biologia, deve ter liberdade para exercer seu ofício, ensinando conceitos pertinentes ao universo científico. O professor deve zelar pelo ensino, procurando constantemente ferramentas, as quais facilitem o aprendizado e, por fim, a contextualização deve ser feita com base no conhecimento da ecologia, do habitat e, sobretudo, da história de vida do indivíduo em estudo. Assim sendo, cremos que a prática educativa do professor de Ciências e Biologia deve ter como principal ponto de apoio a teoria da evolução, como norteadora de todo conhecimento científico pertinente à vida (MEYER; EL-HANI, 2005).

Sabe-se que as ferramentas disponíveis para o ensino, por exemplo, de taxonomia no ciclo básico são: exemplares de coleções, papel, lápis, lupa e, talvez, uma chave dicotômica impressa - ferramentas que não chamam atenção dos alunos quanto à explosão de imagens e sons que podem emanar, por exemplo, de uma TV, ou ainda da tela de um computador. A escola deve constantemente testar novos métodos de ensino, uma vez que seu corpo discente é dinâmico, em constante mudança, e está à mercê das transformações sociais, inclusive daquelas provocadas pelos avanços da ciência e da tecnologia. Uma das ferramentas que têm sido exploradas no ensino, mais especificamente das Ciências Naturais (Biologia, Física e Química), são os jogos. Segundo Piaget (1976) e Vigotski (2007) os jogos são atividades lúdicas que fazem parte do universo da criança, intimamente relacionados ao desenvolvimento mental da infância. É válido lembrar que o potencial de ensino dos jogos não se limita à infância, uma vez que este permanece presente em todas as fases da vida. Segundo Kishimoto (1993), os jogos, além de auxiliarem positivamente a formação cognitiva, são também importantes para o desenvolvimento social e moral dos indivíduos. Entretanto, o uso de jogos, devido ao seu caráter lúdico, sofre discriminação negativa e resistência a esses como ferramentas didáticas, visto que a escola contemporânea tem focado, exclusivamente, no desenvolvimento cognitivo do aluno. Com isso, demorou-se muito a aceitar sua utilização no ensino, ainda hoje é pouco explorado (SPIGOLON, 2006; CAMPOS; BORTOLOTO; FELICIO, 2003). 
Utilização de uma ferramenta multimídia ...

Segundo a cognição situada, devemos compreender a cognição como efeito da interação, mediada pela percepção, pela ação e pela linguagem, entre nossos cérebros, corpos e ambiente (WILSON, 2002; NOË, 2010). Assim sendo, a apropriação de conhecimento por parte do aluno poderá ser mais eficaz em ambientes e aprendizagem que permitam que a cognição se estruture em conexão íntima com a ação e percepção, tornando, por assim dizer, uma aprendizagem mais situada (ANDERSON, 2003). Para a construção destes ambientes, os jogos se configuram como ferramentas adequadas, pois combinam a cognição, ação e percepção. Nesse sentido, ensaiamos a produção de um CD-ROM, o qual disponibiliza, para o aluno, uma chave multimídia para identificação de artrópodes. Apostamos na escolha desse tema, pois acreditamos que este despertará a curiosidade natural dos estudantes do ciclo básico em conhecer e identificar os animais; e por este estar de acordo com os Parâmetros Curriculares Nacionais (PCN) (BRASIL, 1999), os quais sugerem o contato do aluno com a diversidade de espécies no Ensino Fundamental, relacionando-o com os hábitos e habitats; e utilização de critérios científicos para realizar a classificação de animais, vegetais etc. Assim, o objetivo deste trabalho é oferecer novas ferramentas, bem como metodologias, para aperfeiçoar o ensino de ciências, mais especificamente de taxonomia e de zoologia, valorizando a participação ativa, a ação e percepção do aluno, e o uso de suas próprias habilidades cognitivas para observar, detectar as diferenças entre os seres vivos e tomar decisões.

\section{Materiais e método}

\section{Configuração do CD-ROM}

Partimos para a produção de uma animação feita no software da Macromedia, Flash MX, com linguagem de programação Action Script, por apresentar, entre outras vantagens: a edição e animação de imagens gráficas e possibilidade de combinação de vídeos e sons, os quais foram incluídos nas animações. Todos os vídeos foram feitos no programa Windows Movie Maker. É válido ressaltar que o CD-ROM pode ser transportado facilmente de um lugar para outro e ser utilizado em qualquer computador, desde que disponha de um drive de CDROM. Além disso, o material pode ser reproduzido "off-line", sem a necessidade de acesso à Internet e da instalação do programa Flash MX.

No total, o CD-ROM contém recursos para identificação de 22 animais pertencentes a quatro grupos de artrópodes, como: Aracnídeos (aranha, escorpião, opilião e carrapato); Crustáceos (camarão, caranguejo, siri, lagosta e tatu-de-jardim); Myriapodas (lacraia e centopéia) e insetos (abelha, barata, besouro, bicho-pau, borboleta, cupim, gafanhoto, louva-deus, mosca, formiga e libélula).

\section{A escolha do exemplar}

Conforme sugerido pelos PCN do Ensino fundamental de Ciências, optamos por dar ênfase à observação da diversidade das espécies. Dessa forma, o aluno, antes de interagir com a animação do computador, observava uma coleção de exemplares identificados apenas por um número, e escolhia um de seu interesse. Em seguida, ele se encaminhava, com o exemplar 
em mãos, para o computador, a fim de identificar o animal. Para facilitar a visualização dos detalhes e identificação, foram concedidas lupas, manuais e binoculares. No computador, o aluno passava a interagir com a animação (Figura 1A). Nesta, ele podia clicar em "Conheça os Artrópodes", para assistir um vídeo sobre as características gerais deste grupo, ou em "Chave de Identificação". Clicando nesta opção, ele encontrava o layout de escolha de exemplar com 22 botões (Figura 1B). A coleção foi constituída por animais secos, imersos em álcool 70, ou incluídos em resina. Cada exemplar estava identificado apenas por um número, o qual correspondia a um único botão dentro do layout de escolha de exemplar.

Figura 1. 1A - Layout inicial do CD-ROM. 1B - Layout de escolha de exemplar em que o aluno deve escolher o número correspondente ao do seu exemplar de interesse

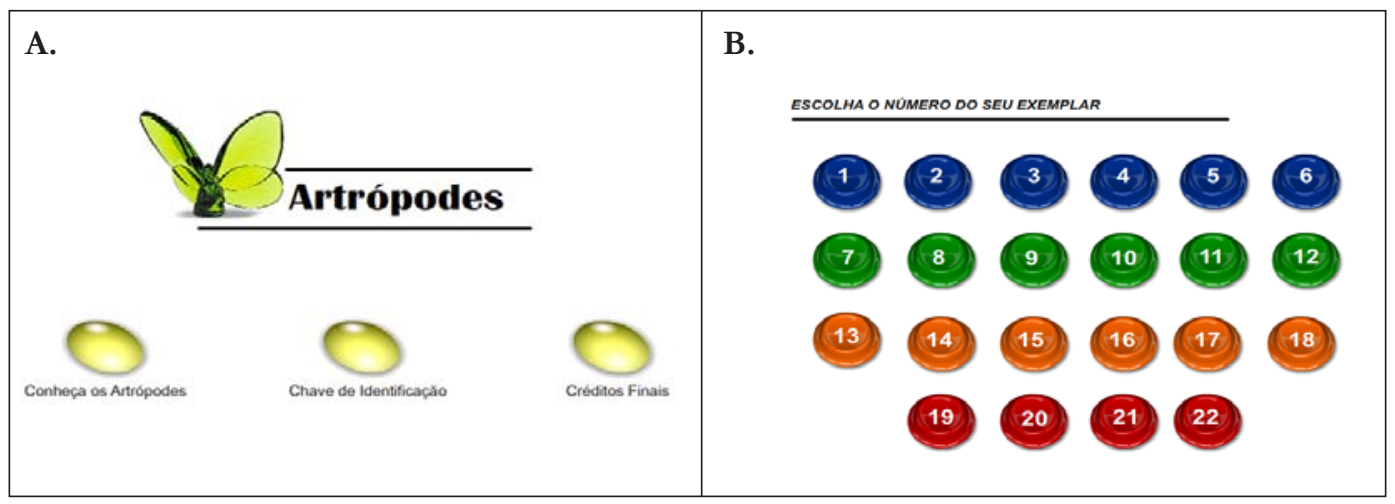

Fonte: elaborado pelo autor

\section{Primeira fase}

Ao fazer a escolha, o aluno entrava em contato com a primeira fase da animação, cujo objetivo era fazê-lo descobrir se o animal de seu interesse era um aracnídeo, crustáceo, myriapoda ou um inseto. Para isso, era exigido que o aluno soubesse, por exemplo, quantos pares de pernas o animal possuía, como era o design corporal; se existiam antenas, quelíceras etc. Para efeito ilustrativo, consideramos que determinado aluno se interessasse pelo animal de número 22. No layout de escolha de exemplar, ele clicava somente no botão de número 22 (libélula). Ao fazer isso, o aluno entrava na sua respectiva chave de identificação e interagia com seu primeiro layout (Figura 2).

Conforme o aluno ia escolhendo suas opções, os layouts da chave mudavam (Figura 2A). Nos exemplos, apenas quando se clicava na primeira opção do primeiro layout da chave sobrevinha a passagem para os próximos (Figura 2B e 2C). Mas, se o aluno, por ventura, errava, isto é, escolhia uma opção da chave errada? Não importava que erro ele tivesse cometido, os layouts continuavam mudando normalmente. Porém, ao fazer pelo menos uma escolha incorreta, o aluno estava fadado a encontrar uma mensagem de erro (Figura 3), na qual, clicando em "voltar", tinha o acesso novamente ao layout de escolha de exemplar. 
Utilização de uma ferramenta multimídia ...

Figura 2. Layouts da chave de identificação, primeira fase, do exemplar de número 22

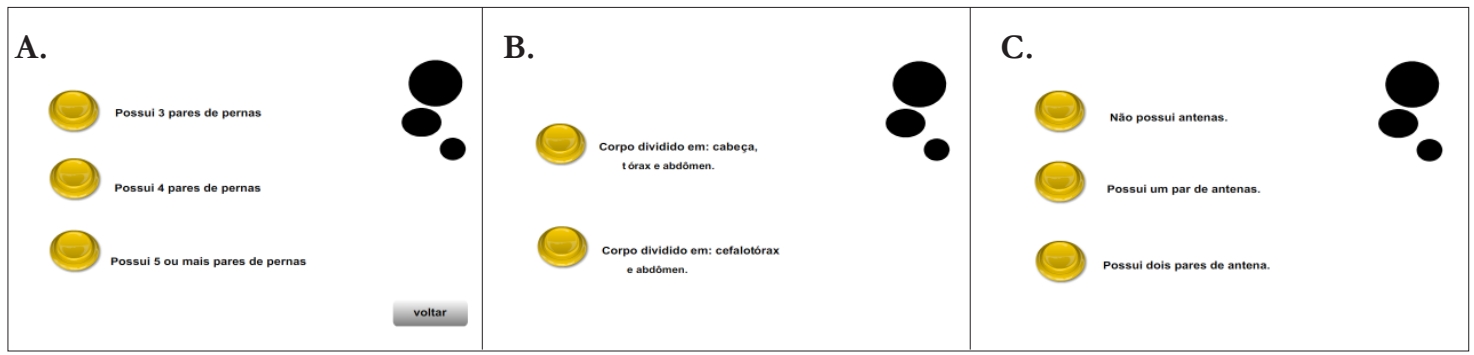

Em 2A, o aluno devia saber quantos pares de pernas o exemplar apresenta - no caso, a libélula é um inseto, portanto, apresenta três pares de pernas; em 2B, era necessário saber sobre o design corporal - todos os insetos apresentam cabeça, tórax e abdômen; em 2C, o aluno devia observar o número de antenas - todos os insetos têm um par de antenas.

Fonte: Elaborado pelo autor

Figura 3. Mensagem de erro. Esta imagem aparece quando o aluno escolhe pelo menos uma opção errada da chave de identificação

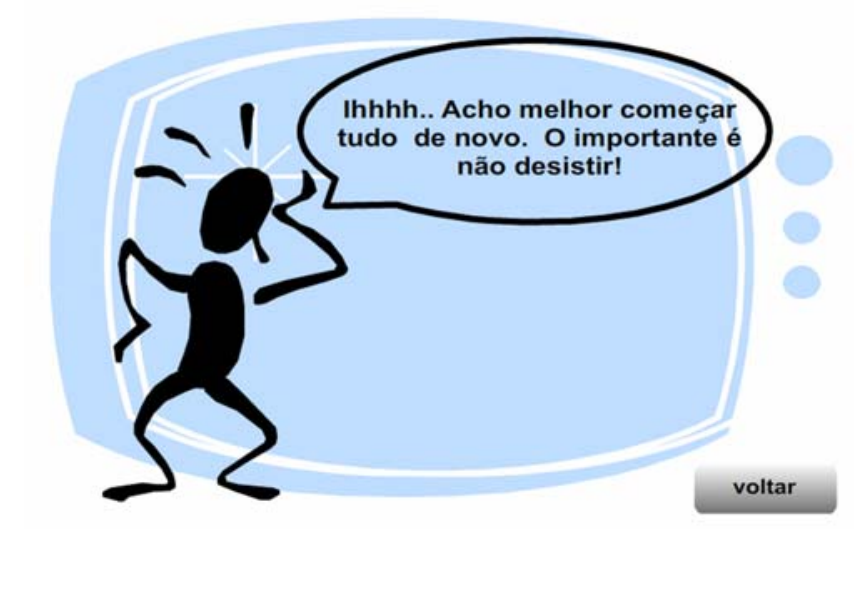

Fonte: Elaborado pelo autor

Dessa forma, o aluno não sabia onde se encontrava o erro - ele necessitava saber todas as características para identificar devidamente o animal. Acreditamos que essa seja a forma mais adequada de se reproduzir o método científico. Além disso, diminuímos as chances da identificação ser feita exclusivamente por tentativa e erro - o que não seria condizente com nossa proposta, que era a de fazer o aluno observar minuciosamente o exemplar de seu interesse e diagnosticar suas peculiaridades. Por outro lado, se o aluno observasse o exemplar 22 e 
Eugênio, T. J. B.

escolhesse corretamente todas as opções da chave, ele tinha acesso a um vídeo que lhe oferecia informações sobre os aspectos biológicos e ecológicos do grupo ao qual o seu exemplar de interesse pertencia - no caso, o dos insetos. Abaixo, exibimos algumas imagens contidas no vídeo, e transcrevemos o exemplo de uma narração, no caso, referente ao exemplar de número 22 (Figura 4). A exibição do vídeo representava o término da primeira fase da animação.

\section{Segunda fase}

Mas pode-se notar que o narrador convida o aluno a observar melhor o animal, uma vez que, na primeira fase, o aluno identificava apenas qual o grupo a que pertencia o exemplar (inseto, aracnídeo, myriapoda ou crustáceo). Sendo assim, o aluno deveria clicar em "2 fase" e prosseguir. Fazendo isso, ele tinha acesso ao layout de escolha de exemplar (segunda fase) semelhante com o layout da Figura 1B. No exemplo, devia-se clicar novamente no botão 22 para se ter acesso à chave de identificação.

Figura 4. Imagens do vídeo (primeira fase) que apresenta aspectos biológicos e ecológicos do grupo dos insetos e, abaixo, transcrição da narração do vídeo
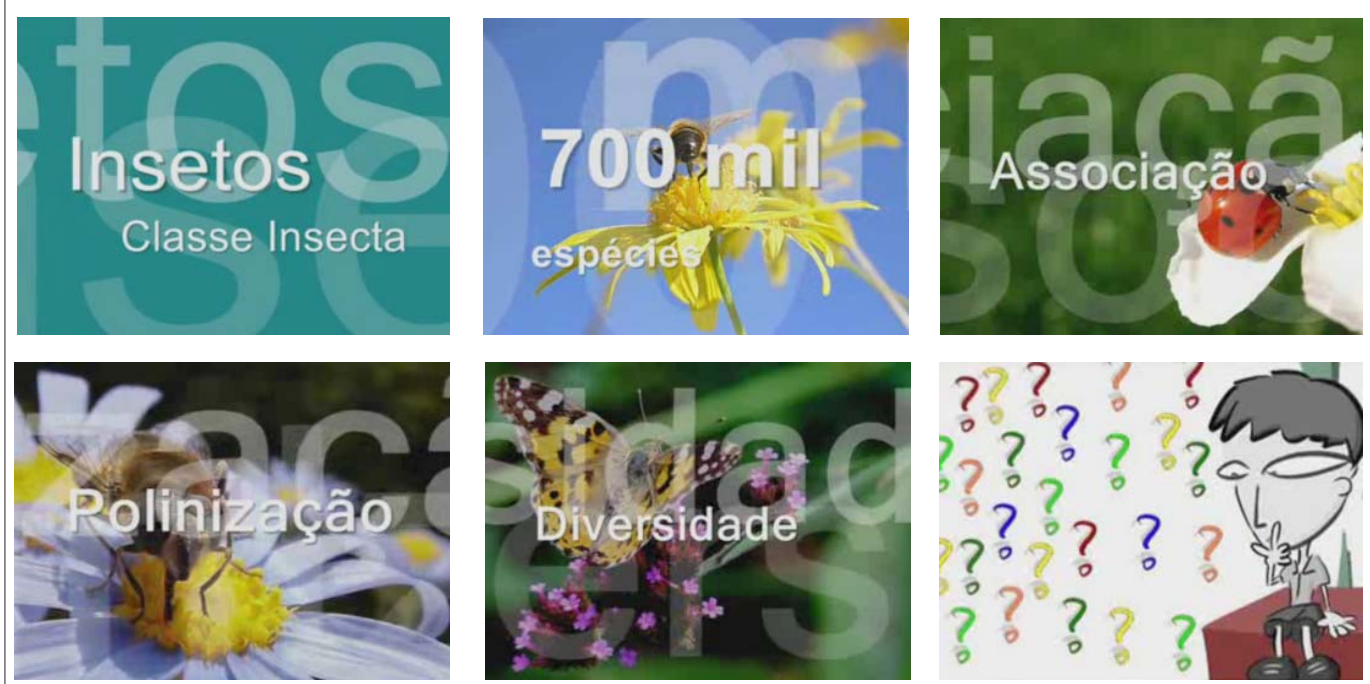

Parabéns! O exemplar que está em suas mãos é um inseto. Os insetos são animais de grande sucesso evolutivo estando hoje representados por mais de 700 mil espécies. O sucesso desse grande grupo praticamente deve-se ao desenvolvimento de antenas, além da organização social de alguns grupo, da grande capacidade reprodutora e da perfeita associação à plantas e outros grupos de animais. Os insetos possuem diversos tamanhos, cores e formas que auxiliam tanto na obtenção de alimento quando na fuga de predadores. Para as plantas, os insetos são muito importantes, já que uma grande quantidade delas são polinizado por eles. Muito bem. Agora você já sabe que o animal que você tem em suas mãos é um inseto. Mas é bom lembrarmos que este grupo é muito diversificado. Por exemplo, dentro dos insetos existem borboletas, gafanhotos, baratas, formigas e muitos outros. E aí? Qual é o inseto que você escolheu? Pois bem, desafio você a observar melhor este animal e encontrar a resposta no final da segunda fase desse programa. Lembre-se! A observação é essencial para o seu sucesso.

Fonte: Elaborado pelo autor 
Utilização de uma ferramenta multimídia ...

A dinâmica era igual à da primeira fase, entretanto, agora eram solicitadas outras características, mais particulares, do exemplar (Figura 5). Se o aluno escolhesse todas as opções corretas, ele teria acesso a outro vídeo. Novamente, abaixo, exibimos algumas imagens e transcrevemos a narração contida no vídeo da segunda fase do exemplar 22.

Figura 5. Layouts da chave de identificação, segunda fase, do exemplar de número 22

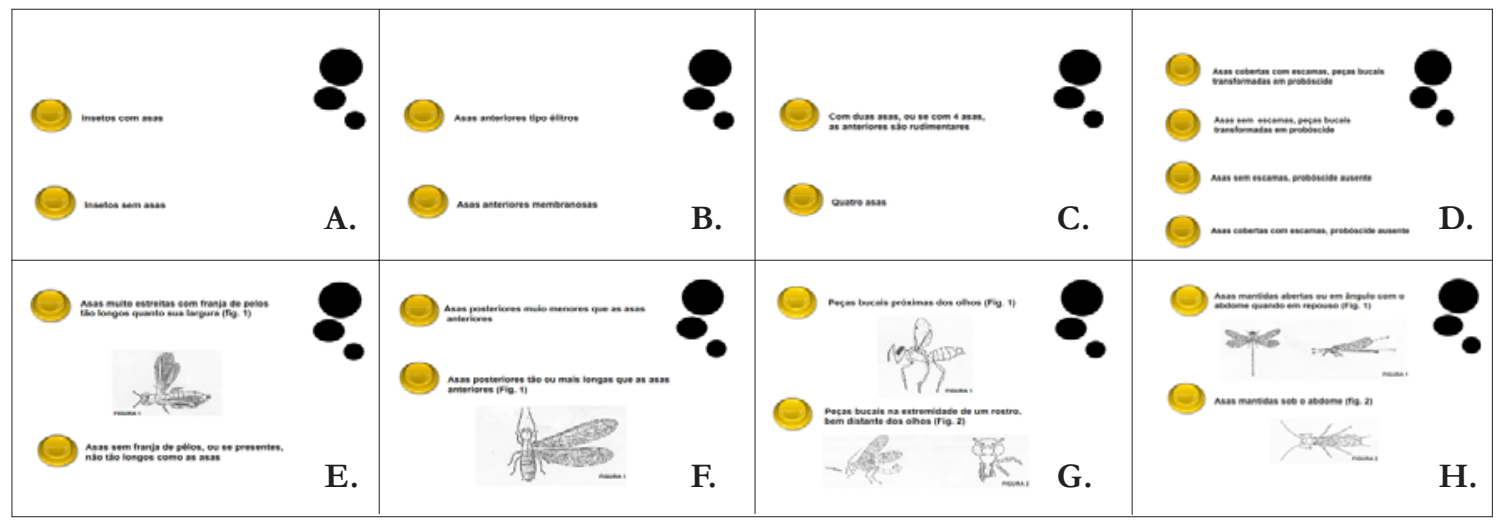

Em A, o aluno deveria saber se o exemplar apresentava asas ou não - no caso, a libélula é um inseto voador, portanto, tem asas; em B, era necessário saber o tipo de asas - a libélula tem uma asa membranosa; em C, o aluno devia observar o número de asas - no caso, o aluno deveria escolher a segunda opção, quatro asas; em D, eram solicitadas informações a respeito do aparelho bucal do animal - libélula é um inseto com asas, sem escamas, e não possui probóscide; em E, eram solicitados, novamente, detalhes das asas - as libélulas não possuem franjas nas mesmas; em F, o aluno deveria comparar o tamanho das asas anteriores e posteriores - as asas posteriores da libélula são tão ou mais longas que as anteriores; em G, pediam-se informações sobre a localização das peças bucais - libélulas apresentam peças bucais próximas aos olhos; em H, o aluno deveria observar se o exemplar possuía asas abertas, em ângulo com o abdome quando em repouso ou sob o mesmo - a primeira opção era a correta.

Fonte: Elaborado pelo autor

A exibição deste vídeo (Figura 6) indicava que o aluno identificou corretamente seu exemplar. Então, ele podia clicar em "voltar", no layout de exibição de vídeo, e escolher outro dos 21 exemplares ainda disponíveis. Para cada exemplar, existia um vídeo, uma nova descoberta a se fazer! 
Eugênio, T. J. B.

Figura 6. Imagens do vídeo (segunda fase) que apresenta aspectos biológicos e ecológicos do exemplar 22 (libélula), e, abaixo, transcrição da narração do vídeo.
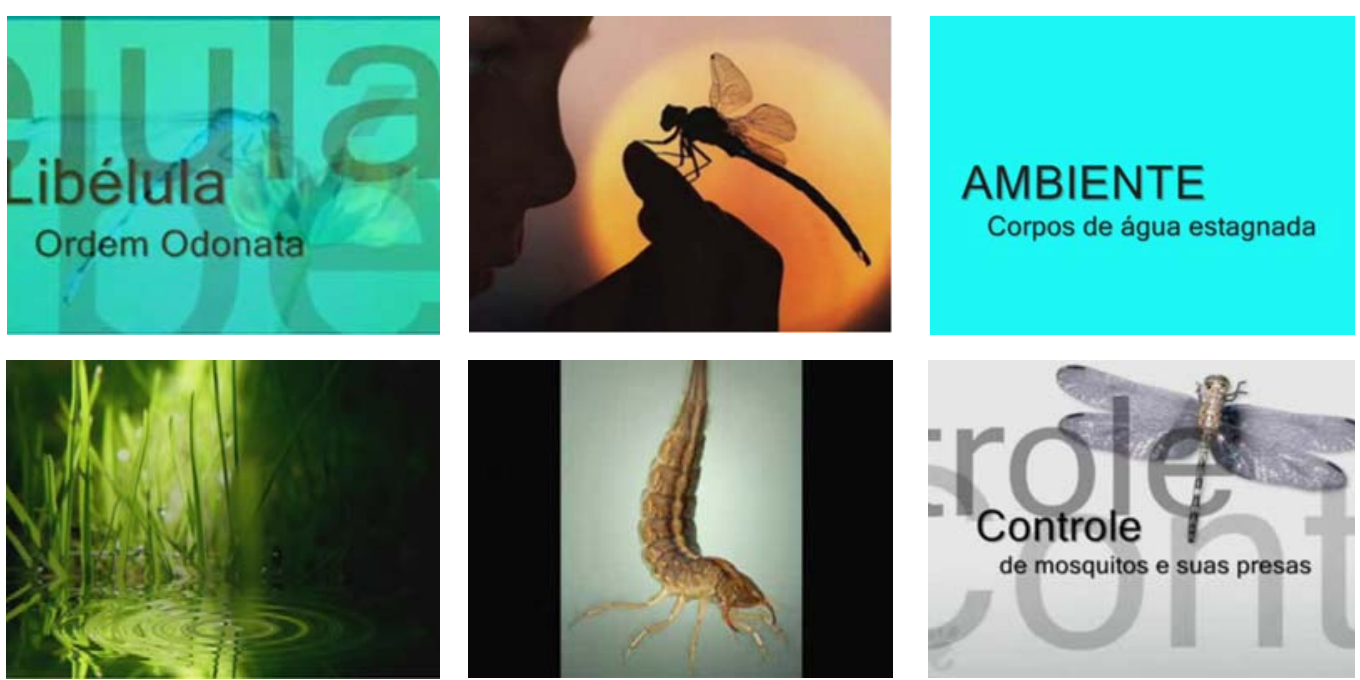

A libélula é um inseto alado pertencente a ordem odonata. Como característica distintiva conta-se o corpo finito com abdome muito alongado, olhos compostos e dois pares de asas semitransparentes. As libélulas são predadoras e alimentam-se de outros insetos tais como mosquitos e moscas. Esse grupo é amplamente distribuído e tem preferência por ambientes nas mediações de corpos de água estagnados como por exemplo, lagos, zonas pantonosas ou perto de ribeirões e riachos. As larvas são aquáticas, carnívoras e extremamente agressivas podendo alimentar-se não só de insetos, mas também de girinos e peixes juvenis. Dentro do seu ecossistema são bastante úteis no controle das populações de mosquitos e suas presas, prestando assim um serviço importantíssimo para o homem.

Fonte: Elaborado pelo autor

\section{Avaliação dos estudantes do Ensino Fundamental}

Aplicamos e avaliamos esta chave multimídia como ferramenta didática em quatro turmas do Ensino Fundamental II (sétimo, oitavo e nono anos) de uma escola privada do município de Parnamirim no estado do Rio Grande do Norte. A avaliação por parte dos estudantes foi dividida em duas etapas: avaliação através de questionário imediatamente após o contato com a chave multimídia, e comparação entre as nota obtidas em exames por escrito de alunos que tiveram e não tiveram contato com a ferramenta didática. Ao todo, 89 alunos participaram das duas etapas da avaliação. Antes da avaliação, consultamos o diretor, o qual permitiu a pesquisa e nos ofereceu todo o suporte necessário. Em seguida, solicitamos, aos coordenadores, informações sobre quais livros os professores de ciências trabalhavam com os alunos. Assim, tomamos conhecimento sobre os livros trabalhados na escola e fizemos um estudo preliminar sobre os conteúdos da coleção "Ciências Naturais - aprendendo com o cotidiano" (CANTO, 2009). Isso foi importante para selecionarmos as turmas que participariam da primeira ou da segunda etapa da avaliação. Nesta coleção, o volume pertinente ao sétimo ano trata mais especificamente da biodiversidade, apresentando, ao aluno, temas como: 
a evolução dos seres vivos (capítulo 4); diversidade da vida animal: vertebrados (capítulos 5, 6 e 7) e diversidade da vida animal: invertebrados (capítulo 8); enquanto que o do oitavo versa sobre fisiologia humana e ambiente, e, o do nono, sobre matéria, energia e reprodução dos seres vivos. Nesse sentido, decidimos aplicar o questionário imediatamente após o contato com a ferramenta multimídia (primeira etapa) apenas em uma turma de oitavo e outra do nono ano, e comparar as notas entre duas turmas do sétimo ano (segunda etapa), visto que este é o momento de primeiro contato dos alunos com um conteúdo disponibilizado pela presente ferramenta didática.

\section{Primeira etapa: avaliação após o contato com a chave multimídia}

Aplicamos um questionário fechado contendo quatro afirmativas de modo a possibilitar que fosse identificada a afinidade que os alunos tiveram com a ferramenta didática, bem como se esta era importante para o aprendizado dos mesmos. Ao todo, 49 alunos, 26 do oitavo e 23 do nono ano (média da idade $=13,9 \pm 0,7$ ), participaram desta primeira etapa. Inicialmente, em sala de aula, o professor apresentava o pesquisador, o qual explicava, em linhas gerais, como seria a dinâmica da aula. Em seguida, os alunos eram encaminhados para a sala de informática da referida escola e executavam a atividade como foi descrita anteriormente. Os alunos recebiam lupas manuais para facilitar a observação de estruturas de difícil visualização. O pesquisador fez uma breve explanação teórica sobre os principais grupos, bem como suas características gerais e as principais diferenças entre os grupos. As identificações dos exemplares, por parte dos alunos, eram feitas individualmente, em dupla ou em trio, dependendo do número de computadores disponíveis para o uso. Os alunos ficavam, em média, 1h40min em contato com a chave multimídia e, em média, cada aluno identificava cerca de 12 exemplares diferentes. Após a atividade, os alunos eram orientados para voltarem para a sala de aula e preencherem um questionário. Para respondê-lo, os alunos deveriam escolher um número, em uma escala Likert, de zero a seis pontos, que melhor representasse a opinião sobre a chave multimídia. Para as cinco afirmativas, o número zero representava que o aluno discordava totalmente, e o número seis significava que o aluno concordava totalmente com a sentença apresentada. Em cada afirmativa, os alunos ainda tinham a possibilidade de responder que não entenderam ou não tinham opinião sobre o tema. Além de, no questionário, o aluno identificar apenas o ano a que pertencia, bem como a sua idade, e opinar sobre as seguintes sentenças: 1) A chave multimídia me facilitou aprender sobre a diversidade de artrópodes; 2) Eu achei divertido aprender sobre os artrópodes com a chave multimídia; 3 ) A chave multimídia é uma ferramenta de difícil manuseio, e 4) Eu prefiro ter aula dentro da sala de aula, com o professor explicando na lousa ao invés de interagir com a chave multimídia.

\section{Segunda etapa: comparação entre o desempenho dos alunos que tiverem e não tiveram contato com a chave multimídia}

Participaram desta etapa quarenta alunos (média da idade $=14,6 \pm 0,6$ ), todos do sétimo ano, separados em duas turmas: A, com 22 alunos, e B, com 18 alunos. Para ambas as turmas, foram ministradas duas horas de aula. Em sala de aula, o professor apresentava o pesquisador, o qual explicava, em linhas gerais, como seria a dinâmica da aula. Era dito para os 
alunos que, na próxima semana (depois de oito dias), eles seriam avaliados, em uma atividade com cinco questões discursivas, sobre os assuntos trabalhos naquela aula. $\mathrm{O}$ valor de cada questão poderia variar de zero a dois pontos. Foi esclarecido para todos os alunos que as notas obtidas na prova por escrito seriam convertidas em $2 / 10$ da média bimestral dos alunos da disciplina de ciências. A atividade de avaliação foi constituída por cinco questões, cada uma com os seguintes objetivos: 1) citar os nomes dos diferentes grupos de artrópodes; 2) elencar as características gerais dos insetos; 3) apontar as diferenças principais entre os aracnídeos, insetos, crustáceos e myriapodas; 4) habilidade em reconhecer e detectar erros cometidos por um personagem fictício na identificação de um artrópode, e 5) habilidade em organizar, com critérios objetivos, um conjunto de objetos (em desenho impresso) em grupos distintos, requerendo do aluno a criação de um modelo simples de chave dicotômica. Todos os alunos tiveram 1 hora para a realização deste exame. As provas foram identificadas por números aleatórios e fez-se uma lista identificando a qual turma as mesmas pertenciam. Em seguida, o pesquisador as juntou e fez a correção. Depois de dadas as notas, o pesquisador, com auxílio da lista feita anteriormente, conseguiu separar as provas. Assim, garantimos, durante a correção, o desconhecimento, por parte do pesquisador, de qual turma aquela prova pertencia.

Através de um sorteio prévio, ficou decidido que os alunos da turma A aprenderiam sobre os artrópodes fazendo uso da chave multimídia e os alunos da turma B através de uma aula convencional, isto é, aquela na qual o professor é apenas um transmissor de conteúdos (ALMEIDA, 2000). Os alunos da turma A eram orientados da mesma forma que os alunos participantes da primeira etapa, porém, não foi solicitado o preenchimento de qualquer questionário. Os alunos da turma $\mathrm{B}$ tiveram uma aula convencional dentro da própria sala de aula. Primeiramente, o professor tratou da biodiversidade e sobre a necessidade e importância, por exemplo, de os biólogos classificarem os seres vivos em grupos distintos. Foi enfatizado que isso era fundamental para a identificação dos mesmos e foi apresentado um modelo simples, esquematizado na lousa, de uma chave dicotômica. Em seguida, discutiu-se, de forma mais específica: o grupo dos artrópodes, bem como seus principais representantes, e a diversidade de forma, habitat e ecologia das espécies. $\mathrm{Na}$ turma $\mathrm{B}$, os alunos copiavam as informações do quadro e eram orientados a acompanhar as ilustrações no livro didático de Canto (2009).

\section{Resultados}

Após a verificação dos questionários e das provas, e anotações da pontuação obtida por cada aluno, os dados foram organizados em planilhas e analisados pelo pacote estatístico SPSS (Statistical Package for Social Sciences). Procuramos fazer uma análise das médias obtidas no questionário aplicado tanto para o oitavo como para o nono ano (primeira etapa), e detectar possíveis diferenças significativas entre o desempenho médio das turmas A e B do sétimo ano no exame escrito (segunda etapa).

\section{Primeira etapa}

De forma geral, observamos que a chave multimídia foi avaliada de forma bastante positiva pelos alunos do oitavo e nono ano (Gráfico 1). Observamos que mais de $90 \%$ dos 
alunos atribuíram notas superiores a três para a primeira sentença, ou seja, concordaram que a chave multimídia facilitava o aprendizado dos mesmos sobre os artrópodes. Apenas $10 \%$ dos alunos atribuíram notas inferiores a três para a segunda sentença, portanto, não concordavam que a chave multimídia era uma atividade divertida. Para a terceira, a qual afirmava que a chave multimídia era de difícil uso, notamos que mais de 90\% dos alunos discordaram dessa sentença, dando notas inferiores a três. Por fim, na quarta sentença, observamos que $80 \%$ dos alunos atribuíram notas inferiores a três, preferindo ter aula sobre aquela temática interagindo com a chave multimídia ao invés de apenas ter aula com o professor explicando na lousa (aula tradicional).

Gráfico 1. Médias e intervalos de confiança de $95 \%$ para as notas (zero representava que o aluno discordava totalmente e seis significava que o aluno concordava totalmente com a sentença) obtidas no questionário aplicado logo após o contato com a chave de identificação aos alunos do oitavo e nono anos

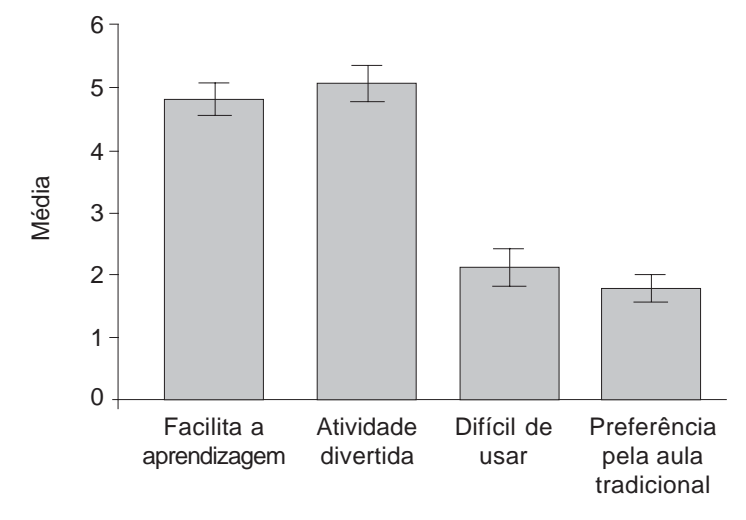

Fonte: Elaborado pelo autor

\section{Segunda etapa}

Primeiramente, testamos se nossos dados eram aderentes à distribuição normal. Para isso, usamos o teste Shapiro-Wilk, indicado para dados menores ou iguais a cinquenta casos. Para todas as questões analisadas, a probabilidade de significância foi maior que 0,05 ( $p>$ $0,05)$. Em seguida, tratamos de fazer uma comparação entre as médias totais dos alunos. $\mathrm{Na}$ média, os alunos da turma A (Média $=7,25 \pm 1,60$ ) tiveram um desempenho mais satisfatório do que os alunos da turma $\mathrm{B}$ (Média $=5,30 \pm 0,90$ ) no exame por escrito, observando-se uma diferença estatística significativa, $\mathrm{t}(38)=-4,55, \mathrm{p}<0,01$. Em análises subsequentes, procuramos examinar as diferenças entre cada questão (Gráfico 2). Nossos resultados apontam que os alunos da turma $\mathrm{A}$, que interagiram com a chave multimídia, obtiveram notas maiores que os 
da turma B apenas quando foi solicitado a eles para: elencarem as principais diferenças entre os grupos de artrópodes (questão 3), $\mathrm{t}(38)=4,06, \mathrm{p}<0,01$; detectarem erros de identificação em uma situação problema (questão 4), $\mathrm{t}(38)=3,15, \mathrm{p}<0,01$, e criarem critérios para classificar um conjunto de objetos com características distintas (questão 5), t(38) = 2,25, p < 0,05.

Gráfico 2. Médias e intervalos de confiança de $95 \%$ para as notas de cada questão do exame escrito aplicado nas turmas A (aula com a chave multimídia) e B (aula tradicional) do sétimo ano

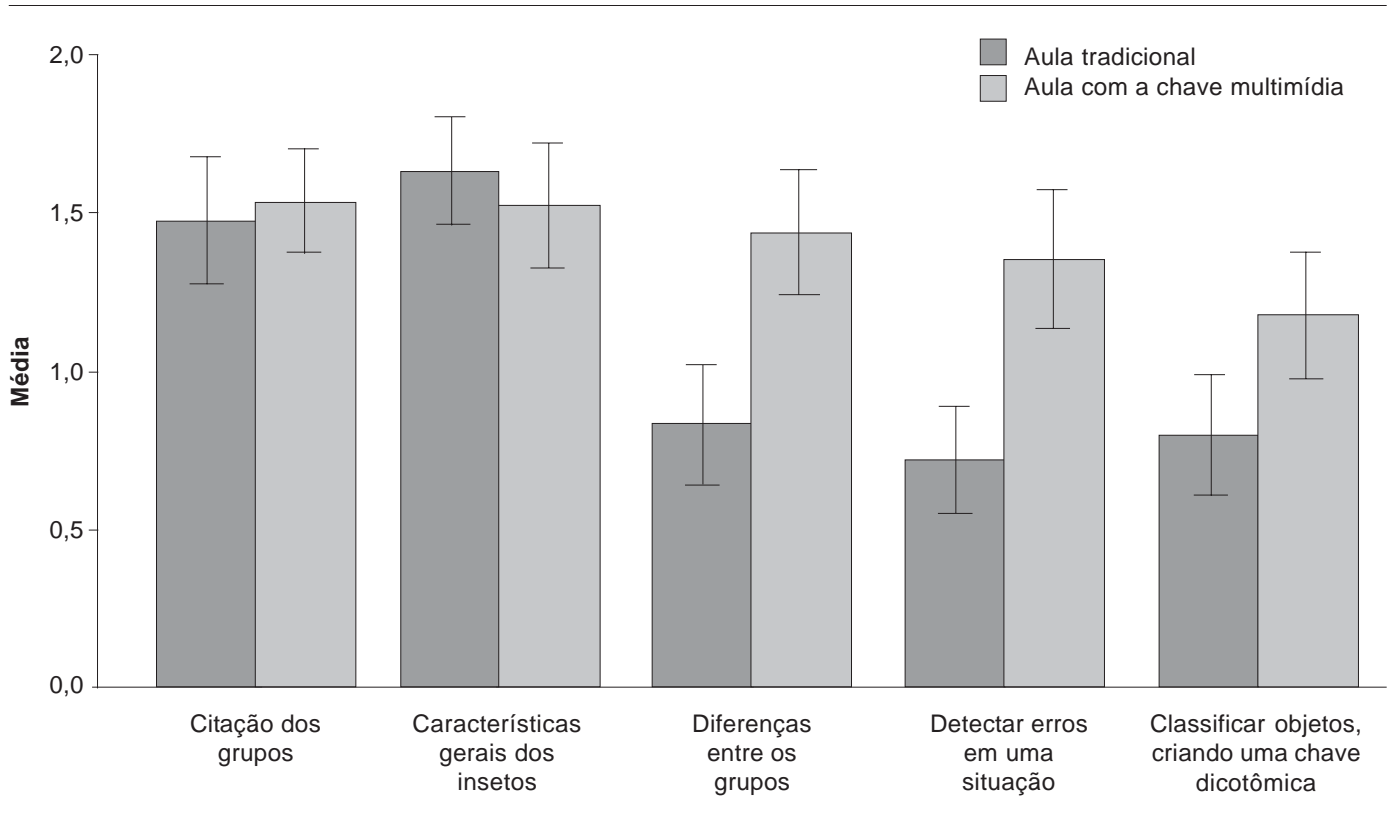

Fonte: Elaborado pelo autor

\section{Discussão}

De forma geral, nossos resultados apontam uma elevada aceitação por parte dos estudantes do oitavo e nono ano, e um impacto positivo no processo de ensino e aprendizagem no que se refere às diferenças de notas encontradas entre as turmas $\mathrm{A}$ e $\mathrm{B}$ do sétimo ano. A maior parte dos alunos parece ter ciência de que a chave multimídia pode facilitar o aprendizado dos mesmos, bem como a considera uma atividade divertida. Outra constatação é a de que a maioria prefere aprender sobre os artrópodes com auxílio da ferramenta multimídia ao invés de assistir a uma aula tradicional. Contudo, deve-se evitar a visão simplista de se atribuir à tecnologia a capacidade de, por si só, sanar todas as dificuldades. Assim, cremos que a tecnologia deve enriquecer e fazer parte de uma proposta pedagógica mais ampla. É imprescindível salientar o papel central do professor para o uso adequado e satisfatório das tecnologias que procuram aperfeiçoar o aprendizado. É essencial que ele esteja, mais do que ninguém, preparado para lançar mão desse recurso e, sobretudo, que ele tenha uma ideia consciente do porquê dessa utilização. 
Provavelmente, os alunos consideraram a chave multimídia uma atividade divertida, uma vez que ela exige a movimentação ativa do aluno, desde a escolha do exemplar até o manuseio do exemplar para análise do mesmo, e propõe uma situação de desafio e investigação. Segundo Noë (2010), a cognição é um produto da interação entre os nossos cérebros, corpos e ambiente, mediada pela percepção e ação. Assim sendo, quanto mais o ambiente de aprendizagem fomentar a movimentação do corpo, a exploração de ambientes, bem como a percepção e a ação, mais favorável será o aprendizado. Esta é uma ideia diametralmente oposta em relação aos ambientes de aprendizagem que tipicamente são instaurados nas salas de aulas de ciências e biologia, nas quais os alunos não usam o corpo como elemento de construção de suas ideias, na medida em que apenas escutam o professor, prestando atenção no que ele diz e nas informações que ele anota no quadro e, a partir daí, constroem uma compreensão do assunto abordado. A análise dos dados obtidos com os alunos do sétimo ano reforça ainda mais esta tese.

Observamos que, no geral, os alunos da turma A (que interagiram com a chave multimídia) tiveram um desempenho melhor do que os alunos da turma B (que assistiram a uma aula tradicional), sugerindo um impacto positivo da chave multimídia no processo de ensino e aprendizagem. A análise individual das cinco questões propostas nos aponta que, em duas questões, não houve uma diferença significativa entre as duas turmas. Inclusive, na questão 2 , os alunos que assistiram aula tradicional tiveram um desempenho médio maior. É válido lembrar que essas duas questões solicitavam respostas que podiam ser facilmente memorizadas pelos alunos, como os nomes das classes dos artrópodes e as características gerais dos insetos. Entretanto, as questões 3, 4 e 5 requeriam habilidades cognitivas além da memória como, por exemplo: comparar e diferenciar os grupos de artrópodes, detectar erros e elaborar critérios para montagem de uma chave de identificação. Foi nessas três últimas questões que percebemos diferenças significativas nos desempenhos entre os alunos das duas turmas - os alunos que interagiram com a ferramenta multimídia obtiveram notas maiores. Nesse sentido, acreditamos que a presente proposta se configura como uma ferramenta poderosa para a construção de ambientes que combinam cognição, ação e percepção, permitindo, assim, uma aprendizagem mais situada (ANDERSON, 2003).

Embora cientes das dificuldades, e de que muito ainda está por ser feito no que se refere à inserção da técnica computacional como recurso didático nas escolas, acreditamos que nossa pequena experiência já nos permitiu perceber o enorme potencial que a tecnologia pode oferecer para o trabalho do professor. Contudo, é de suma importância explicitar as limitações que toda tecnologia apresenta. No que tange à proposta da chave multimídia, é necessário destacar que as chaves de identificação não têm parcimônia. O princípio de parcimônia é largamente empregado na Ciência e pode ser compreendido como "o mais simples prevalece". No caso, existem exemplares que poderiam ser identificados, por exemplo, por uma única característica. Abrimos mão desse importante princípio, uma vez que ele poderia tornar muito fácil e talvez desinteressante a identificação de inúmeros exemplares. Além disso, quando se identifica o exemplar, o aluno assiste a um vídeo sobre a ecologia e comportamento do mesmo. Entretanto, a chave não contempla a origem evolutiva, bem como a história de vida do animal. Nesse sentido, o CD-ROM, por si só, não oferece uma visão integrada e norteada pelos pressupostos evolutivos - conforme é recomendada nos PCN de Ensino Médio (BRASIL, 1999). Por isso, enfatizamos a importância do professor, o qual deve contextualizar e 
oferecer um suporte lógico para o aluno compreender, assim como se sentir interessado e motivado para ampliar seus conhecimentos de ciências e biologia.

Todavia, apesar de suas limitações, a chave multimídia apresenta inúmeros benefícios e utilidades no processo de ensino-aprendizagem. Além de unir cognição, ação e percepção, o CD-ROM não se reduz somente à consulta a uma fonte de informações e ilustrações, e o aluno não é encarado apenas como um telespectador. Pelo contrário, é considerada e incentivada a participação do aluno; desde a escolha do exemplar até a sua identificação, o aluno é tido como sujeito ativo e construtor do seu próprio conhecimento. $\mathrm{O}$ aluno não necessita decorar, mas apenas fazer uso de suas habilidades cognitivas e observar, detectar as diferenças e tomar decisões. A dinâmica da chave multimídia, portanto, é diametralmente oposta à aprendizagem mecânica, uma vez que procuramos nos apoiar no conceito de aprendizagem significativa desenvolvido por David Ausubel (MOREIRA, 2006; AUSUBEL, 2003). Segundo esse autor, a aprendizagem se daria pelo armazenamento de informações, as quais seriam transformadas em ideias e, posteriormente, agrupadas e alocadas na mente do indivíduo em ordem de importância. Essas ideias poderiam ser acessadas e manipuladas, no futuro, pelo aluno, através da organização e integração dos conteúdos apreendidos significativamente, isto é, os que têm algum sentido para o aluno - nesse processo, a informação deveria interagir e ancorar-se nos conceitos prévios já existentes (TAVARES, 2008).

Paulo Freire (1997, p. 30) diz que "ensinar exige respeito aos saberes do educando". Dessa forma, o professor deve ter ciência de que o aluno, antes de se apropriar dos conteúdos curriculares, está impregnado pelos saberes construídos pela prática comunitária. Assim, o professor participaria da formação do aluno não causando uma ruptura desses saberes com os ditos científicos, mas, sim, superando suas diferenças e distâncias. Entre outras palavras, o professor agiria no sentido de criticizar a curiosidade ingênua do aluno, a qual está associada ao senso comum - possibilitando o surgimento do senso crítico, isto é, da curiosidade epistemológica no educando.

Nesse sentido, no que tange à proposta de uso da chave multimídia como recurso didático, o aluno é guiado pela sua curiosidade ingênua, sobretudo, na escolha ativa do exemplar de seu interesse. Entretanto, na medida em que o aluno interage com a chave multimídia, novos conceitos são introduzidos e apropriados conforme lhe fazem sentido, isto é, lhe são significativos. Não vemos outra implicação disso senão a citada por Freire (1997), ou seja, de que, fazendo isso, estamos criticizando o senso do aluno.

Tendo em vista o exposto, concluímos que a presente proposta e ferramenta de ensino de taxonomia e zoologia para Ensino Médio é válida, visto que ela permite ao aluno reproduzir virtualmente o método científico no processo de identificação de qualquer animal. Além disso, disponibiliza, de maneira diferenciada e sofisticada, informações e conceitos pertinentes à formação de um indivíduo provido de uma visão mais abrangente e crítica sobre aquilo que a biologia se propõe a investigar, isto é, a vida. 
Utilização de uma ferramenta multimídia ...

\section{Referências}

ALMEIDA, M. J. P. M. Expectativas sobre o desempenho do professor de física e possíveis conseqüências em suas representações. Ciência \& Educação, Bauru, v. 6, n. 1, p. 21-29, 2000 .

ANDERSON, M. L. Embodied cognition: a field guide. Artificial intelligence, Amsterdam, v. 149, n. 1, p. 91-130, 2003.

AUSUBEL, D. Aquisição e retenção de conhecimento: uma perspectiva cognitiva. Lisboa: Plátano, 2003.

BRASIL. Ministério da Educação. Parâmetros curriculares nacionais: Ensino Médio: ciências da natureza, matemática e suas tecnologias. Brasília: Secretaria de Educação Média e Tecnológica, 1999.

CAMPOS, L. M. L.; BORTOLOTO, T. M.; FELICIO, A. K. C. A produção de jogos didáticos para o ensino de ciências e biologia: uma proposta para favorecer a aprendizagem. Cadernos dos Núcleos de Ensino, São Paulo, p. 35-48, 2003. Disponível em: <http:// www.unesp.br/prograd/PDFNE2002/aproducaodejogos.pdf>. Acesso em: 16 maio 2009.

CANTO, E. L. Ciências naturais: aprendendo com o cotidiano. 3. ed. São Paulo: Moderna, 2009.

FREIRE, P. Pedagogia da autonomia. 6. ed. Rio de Janeiro: Paz e Terra, 1997.

FUTUYMA, D. J. Biologia evolutiva. 2. ed. Ribeirão Preto: SBG; CNPq, 2002.

KISHIMOTO, T. M. Jogos tradicionais infantis: o jogo, a criança, a educação. 8. ed. Petrópolis: Vozes, 1993.

MAYR, E. O desenvolvimento do pensamento biológico. Brasília: Universidade de Brasília, 1998.

MEYER, D.; EL-HANI, C. N. Evolução: o sentido da biologia. São Paulo: Ed. da Unesp, 2005.

MOREIRA, M. A. A teoria da aprendizagem significativa e sua implementação em sala de aula. Brasília: Universidade de Brasília, 2006.

NOË, A. Out of our heads: why are not your brain, and other lessons of the biology of consciousness. New York: Hill and Wang, 2010.

PIAGET, J. Psicologia e pedagogia. Rio de Janeiro: Forense Universitária, 1976.

SPIGOLON, R. A importância do lúdico no aprendizado. 2006. 44f. Trabalho de Conclusão de Curso (Graduação em Pedagogia) - Faculdade de Educação, Universidade Estadual de Campinas, Campinas, 2006.

TAVARES, R. Aprendizagem significativa e o ensino de ciências. Ciências \& Cognição, Rio de Janeiro, v. 13, p. 94-100, 2008. 
Eugênio, T. J. B.

VYGOTSKY, L. S. A formação social da mente. São Paulo: Martins Fontes, 2007.

WILSON, M. Six views of embodied cognition. Psychonomic Bulletin \& Review, Austin, v. 9, n. 4, p. 625-636, 2002.

Artigo recebido em 08/08/2011. Aceito em 15/02/2012. 